\title{
An Important Clarification Regarding Foundation Funding for Hispanics/Latinos in the United States and for Latin America
}

Please note that this report, first published in December 2011, was updated in February 2012 to reflect more precise language around the findings.

In the study, Foundation Funding for Hispanics/Latinos in the United States and for Latin America, the Foundation Center reports that, "Over the past decade, U.S. foundation dollars explicitly designated to benefit Latinos have remained steady, comprising about 1 percent of total foundation funding." The following context is critical to an accurate understanding of this finding:

- The finding is based on an analysis of information gleaned from two sources: 1) foundation self-reports of their giving, and 2) publiclyavailable information from the web sites of recipient organizations.

- It does not represent all giving awarded by foundations that may have benefited Hispanic and Latino communities.
- It represents only that giving that was clearly described as intended to benefit Hispanics or Latinos.

The Foundation Center's methodology and its limitations are explicitly laid out on page 2 of the report and reiterated in the Summary on page 14 .

It is not possible, given available data, to determine exactly what percentage of grantmaking by U.S. foundations benefits Hispanic or Latino communities. Additional research would be needed to create a more comprehensive estimate.

The Foundation Center welcomes feedback on its work, and invites you to voice your opinion on our blogs, PhilanTopic and Transparency Talk.
ADDITIONAL RESOURCES

Other studies conducted by the Foundation Center and other organizations have attempted to derive more comprehensive estimates for grantmaking benefiting communities of color. Please see, in particular:

- Embracing Diversity: Foundation Giving Benefiting California's Communities of Color

- Grantmaking to Communities of Color in Oregon

- Broad Benefits: Health-Related Giving by Private and Community Foundations (produced by the Philanthropic Collaborative, in cooperation with the Foundation Center) 